\title{
Cognitive Poetics Interpretation of the Viewpoints in Unselected Road
}

\author{
Lu Feng \\ School of Foreign Studies, Weinan Normal University, Weinan, Shaanxi, 714000
}

\author{
Keywords: Cognitive Poetics; Unselected Roads; Poetry Viewpoints
}

\begin{abstract}
On the basis of philosophy and cognitive science, cognitive poetics integrates the theories of literature, psychology and narratology to understand the limited factors of poetry and carry out multidimensional and cross-domain cognitive connections so as to effectively understand the deep meaning of poetry. The point of view involved in poetry is an issue related to creation. It reflects the authors and reader's cognitive perspectives and attitudes. There are many ways in classifying poetic perspectives. Combining with the creative features of Unselected Roads, the paper interprets the poem in aspects like space-time, narration, perception and concept.

Unselected Road is a classic poetry by laureate Robert Frost, one of his masterpieces. In this poem, the poet, with his usual style of writing, refined poetic ideas from ordinary things and found profound and universal philosophy of life from personal feelings, shows us a rich speculative and aesthetic atmosphere. The same is true for the Unselected Road. The poet introduced a series of reveries and reflections on the road between forests, giving the audience a new understanding of life and between the present and past.
\end{abstract}

\section{Graphical / Background Perspective Interpretation of Unselected Roads}

Graphic / background is actually portrayed from graphic to background. It belongs to the theoretical category of psychology, including the principle of graphic / background separation, the conversion and displacement. It takes the subject or the focus of attention as a graphic independently, and desalinates the environment in which it is blurred as the background. Then the clear graphics is separated from the blurred background. From the point of view of literary reading, the focus of attention is constantly changing. Therefore, the graphics and background are constantly being drawn and fixed. This process is based on the exchange of ideas and feelings with text as the carrier for the audience and the author to resonate and create similar aesthetic enjoyment. In the process of reading, the graphic and the background cooperate with the audience to deeply penetrate into the core of the artwork, touch the author's writing intent, thoughts and emotions, and understand the connotation and denotation conceived thereby to achieve artistic sublimation.

The Unselected Roads contains four sections, the first section runs straightly into the theme, it describes woods, two sideways with simple words, with the opening of the section, in the audience's imagination, the yellow wood desalts as the background, two sideways become the main body of the imagination. Then it turns out that "I" stand at one of the crossing, seeing the way it goes and finally it fades away into the woods while the other sideway is still unseen in the background. Then it comes to the second section, where the crossing mentioned in the first section turns to be the background and the other sideway starts to be seen as the main part of the picture. The last two sections recur the picture based on the memory, "I" again go back into the woods with fallen leaves everywhere and only one road can be selected, so "I" give thoughts about the road not taken and meditate about the connection between the choice once made and the memory "I" have today. In general, the images in the poem continuously change with the perspective of the poet in the main picture and background, resonate with the audience to create a figurative pattern, and to feel the power of feeling in the mood. 


\section{To interpret the poem Unselected Roads in view of time and space}

The view of time and space includes the change of time and space, seeing from the whole structure, the poem begins from the vast expanse of space to the woods with fallen leaves, and from the field of vision back to a small scene, realizing the first shift of space. The poet then chose one of the ways to walk, the scene is still in the woods, but with the line of sight, the scenery changes from the ground with fallen leaves to the ground with fragrant grass, so that the audience can feel the quiet and artistic conception.

Unselected Roads shows the shift of space from the time line of the past, the present and the future, and it correlates with the main part of the poem-the choice of the road. It states that the choice you made has something to do with your life experience, as the first and second sections of the poem describe that the situation "I" am facing with is current, with no experience to refer to nor the guidance of the prediction of the future, that's the reason why "I" stayed long hesitating over the crossing.

Focusing on the perspective of past, the third section reviews the roads and the choices the author went through. "That morning leaves falling everywhere" is in line with the first sentence of the first section with the integration of two time nodes. While in terms of content, the first section deals directly with the situation of choice and the third section exams the choice on the basis of experience. The poet does not explain the result from the perspective of choice, but expounds the regret that exist in a specific space-time from the characteristics of choice. In the fourth quarter, he places his perspective on the future and reviews again several years later. This piece of woods and these two roads still carry known and unknown things, which is the inevitable result of our choice. The transformation of time and space elevates the poetry from the creation of images and artistic conceptions to the philosophical height enriched with critical thinking.

\section{Interpretation of Unselected Roads from the narrative point of view}

In this poem, "I" is the only narrative viewpoint. From a narrative perspective, this point of view contains two levels, narrative self and empirical self. As the main line of poetry and also the leading proponent of thoughts and emotions, narrative ego took the audience into the yellow woods in the first section, faced two ways to choose and then entered the situations of recalling. In the primary atmosphere created by narration, audience's empirical self is stimulated by narrative ego, a spectator, enters the preconceived artistic conception with the rhythm of narration, perceives the poet's profound connotation and triggers the connection of experience self and narrative self into resonance.

In the fourth section, narrative self is converted to the experiential self. From the point of looking back, the author thinks about the experience and choice in the forest. The narrative contexts change from experience to recalling and then to prospect in the fourth section. The reading experience of the audience follows the change of perspective, from the external choices of roads to the divergent thinking of life and events, which is a qualitative leap in experience. Multiple experiences of reading are established, including reading pleasure, deep thinking and introspection with deep spiritual experience.

\section{Perceptual Perspective Interpretation of Unselected Roads}

In the process of reading literary works, the perspective of perception is a deep exploration of the text in the beginning and then to the content. It is a process from the unknown to the discovered and the known experience, from which new feelings and new information are obtained. It is in line with the law of cognition. The starting point of perception is based on the text, which is the beginning of speech. The end of perception is the reception of new information and reaches the inside of speech content.

In the first five sentences, the sentiment conveyed by the poet is the emotion of confronting choices. The setting of the context makes the person feel they are personally on the scene. The 
straightforward language makes it easy for people to enter into the poem. Together with the poet, it evokes a similar memory experience, and establishes a good beginning for reading. The second five starts with "then", and takes over the confusion of the previous section and opens up the reflections of the latter section. Where will the other road go? The poet uses the metaphor of the forest path to make choices. When the author wrote this poem, he was not overly perplexed. It is precisely the experience of life to life and the age at which profound meaning and meaning are gradually realized. Therefore, the poet borrows the metaphor of life's choices and trends to come up with new ideas. Each choice can reap the scenery. This mentality and knowledge is a great mood for the audience. At the same time, the fear of the unknown is resolved into a beautiful firmly belief and pursuit.

\section{Interpretation of Unselected Roads from the Idea Perspective}

The concept of point of view involves the spiritual level, embodied in a kind of attitude and viewpoint. In the poetic text, the viewpoint of concept can be interpreted from the basic words such as modal words and adverbs. The attitude and viewpoint of the author are integrated into the text and become the spiritual orientation that influences the reading experience of the audience. Of course, attitudes toward things as well as systems of values have a fundamental impact on the poet's creation. Text is the inner projection of the poet and also a way for the inner world to appear.

Interpretation of the concept of point of view needs to pay attention to the recognition of key words, such as the words that embody ideas, more able to establish a resonance between the audience and the poet. The word Road in the Unselected Roads appears frequently in poetry. Two roads is also a multiple occurrences, the sentence: Two roads diverged in a wood, appears at both ends and the head, the structure is complete and echoes, at the same time reiterated the author's experience in the creation: the two roads must be chosen, life choices inevitably leave regret, but only to go, will meet the beautiful scenery, will get a real experience. The poet's point of view builds the atmosphere and space in the minds of the audience through the bridge of the text, or makes no comments or direct expression of opinion, stimulates imagination and reflection, and thus profoundly comprehends the literary meaning of poetry.

\section{Conclusions}

Cognitive poetics provides a variety of ways for the interpretation of poetry. Different interpretations of different perspectives can have different reading experience, which helps to excavate the ideological and deep meaning of poetry, understand the intention of poet creation, and achieve effective communication between reading and writing. Poetry point of view for the creation, it helps to highlight the theme, rendering mood, it can be a creative skill, it can also be a writing style. From the perspective of cognitive poetics, the interpretation of Unselected Roads from the point of view of poetry can not only deepen the understanding of inner meaning in the works, but also gain philosophical insight and comprehension from the poem.

\section{References}

[1] Wang Yalei. Cognitive Study of Robert Frost'The Road Not Taken [J]. Journal of Qiqihar University (Phi\& Soc Sci), 2016(03):123-126.

[2] Wang Xiaojun. Interpretation of Frost's 'Unselected Roads' from the Perspective of Graphical Theory of Cognitive Poetics [J]. Science \& Technology Vision, 2016(25):110-111. 